\title{
Comunicação
}

[Communication $]$

\section{Estudo dos métodos de rotina diagnóstica de mastite no leite de éguas}

[Study of routine diagnosis methods of mastitis in mares]

R.G. Motta, M.G. Ribeiro, H. Langoni, D.G. Motta, M.M.J. Franco, A.C.S. Almeida, I.B.M. Perrotti, F.J.P. Listoni, B.D. Menozzi

Faculdade de Medicina Veterinária e Zootecnia - UNESP

Caixa Postal 560

18.618-970 - Botucatu, SP

Na América do Sul, o leite equino não é comumente utilizado para consumo humano. Porém, em países como a Alemanha e a França, o leite de égua é utilizado em hospitais, na alimentação de crianças nascidas de parto prematuro (Morais et al., 1997). Dentre os mamíferos, o leite de éguas é o que apresenta maior semelhança com o leite da mulher, em virtude da alta digestibilidade, do baixo teor proteico, do alto teor de lactose e do equilíbrio da relação albumina-globulina (Morais et al., 1997; Prestes et al., 1999). A égua, em geral, supre a necessidade de leite do potro, que se constitui na única fonte de nutrição nas suas primeiras semanas de vida, fator essencial para a sobrevivência do recém-nascido (Smith, 2003).

A ocorrência de mastite em éguas é considerada baixa se comparada aos ruminantes domésticos (Radostits et al., 2007). Ocorre com maior frequência na lactação e secundariamente no período seco, geralmente como consequência de ferimentos nas mamas ou nos tetos (McCue e Wilson, 1989). Os microrganismos mais frequentemente isolados do leite e das secreções de glândulas mamárias dos equídeos são Streptococcus beta-hemolíticos, Staphylococcus spp. (Radostits et al., 2007), Pseudomonas aeruginosa, Actinobacillus spp. e enterobactérias (Prestes et al., 1999). Na suspeita de mastite, é fundamental o cultivo microbiológico do leite para se firmar o diagnóstico (Koterba et al., 1990), visto que os métodos de diagnóstico da mastite em vacas, particularmente o California
Mastitis Test (CMT) e a contagem de células somáticas, não estão padronizados para a espécie equina (Smith, 2003; Ribeiro, 2008). O presente estudo investigou, em 55 éguas em lactação, os principais métodos de rotina de diagnóstico de mastite em vacas, incluindo a caneca telada de fundo escuro, CMT, CCS, o perfil microbiano do leite e a sensibilidade dos isolados aos antimicrobianos.

Foram utilizadas 55 éguas adultas em lactação, entre 15 e 150 dias pós-parto, com idade entre quatro e 16 anos, primíparas ou multíparas - um a nove partos -, de diferentes raças e cruzamentos, distribuídas em: 18 (32,7\%) mestiças, 14 (25,4\%) Quarto de Milha, 12 (21,8\%) Mangalarga, quatro $(7,3 \%)$ Crioula, quatro $(7,3 \%)$ Appaloosa e três $(5,4 \%)$ Paint Horse. As éguas eram utilizadas em atividades de entretenimento, esporte, tração e como receptoras de embriões.

Foram avaliadas 110 mamas de 55 éguas. O diagnóstico de mastite clínica foi firmado nos animais que apresentaram alterações no leite presença de grumos, pus, dessora ou estrias de sangue - no teste da caneca telada de fundo escuro (Tamis), sinais de inflamação na glândula mamária - dor, edema, hiperemia, hipertermia ou nódulos - e sistêmicos (Radostits et al., 2007). A presença de infecção mamária subclínica foi caracterizada utilizando-se o CMT (escores $1+$ a $3+$ ). 
Procedeu-se à colheita de 55 amostras de leite (5 a $10 \mathrm{~mL}$ ), sob a forma de pool das duas mamas de cada égua, após antissepsia dos canais dos tetos, utilizando solução de álcool-iodado $2 \%$. Após desprezar os primeiros jatos de leite, foram colhidas as amostras em frascos esterilizados para o envio ao laboratório para o cultivo microbiano, em até 24 horas, acondicionados em temperatura de refrigeração $\left(4\right.$ a $\left.8^{\circ} \mathrm{C}\right)$. Todas as amostras de leite foram semeadas em ágarsangue bovino desfibrinado (5\%) e ágar MacConkey, incubadas em aerobiose a $37^{\circ} \mathrm{C}$, por 72 horas. Os microrganismos isolados foram identificados com base nas características morfotintoriais, bioquímicas e de cultivo (Quinn et al., 2005). O perfil in vitro de sensibilidade microbiana (antibiograma) dos isolados foi realizado pela técnica de difusão com discos (Clinical..., 2006), utilizando os seguintes antimicrobianos: ceftiofur $(30 \mu \mathrm{g})$, enrofloxacina $(5 \mu \mathrm{g})$, florfenicol $(30 \mu \mathrm{g})$, gentamicina $(10 \mu \mathrm{g})$, penicilina (10UI), sulfatrimetoprim $(25 \mu \mathrm{g})$, azitromicina $(15 \mu \mathrm{g})$, amicacina $(30 \mu \mathrm{g})$ e norfloxacina $(10 \mu \mathrm{g})$. Simultaneamente foi colhido leite do pool das mamas das 55 éguas para contagem eletrônica de células somáticas. $\mathrm{O}$ material foi acondicionado em frascos contendo o conservante bronopol, encaminhado em até 48 horas e avaliado pelo equipamento SomaCount
300, pelo método de citometria de fluxo (Arashiro et al., 2008).

Das 55 éguas em lactação, duas (3,64\%) apresentaram mastite clínica, com sensibilidade dolorosa à palpação da glândula, presença de nódulo, abscesso isolado, pus viscoso e leite com grumos evidentes na prova da caneca telada. No teste do CMT, $13(23,6 \%)$ éguas acusaram reação escore $1+, 7(12,7 \%) 2+$ e $10(18,2 \%) 3+$. Em 23 (41,8\%) fêmeas não se observou qualquer reação no CMT.

O cultivo microbiológico do leite revelou $\mathrm{o}$ isolamento de 71 estirpes de microrganismos, provenientes de $47(85,4 \%)$ animais (Tab. 1). Nas duas amostras de leite de animais com mastite clínica foram isolados Staphylococcus aureus ( $S$. aureus) e Arcanobacterium pyogenes (A. pyogenes). Das 55 amostras de leite cultivadas, em oito $(14,6 \%)$ não foi obtido o isolamento microbiano. A presença de éguas com isolamento microbiano no leite, reagentes no CMT escores $1+, 2+$ e $3+$, foi observada em, respectivamente, $12(25,5 \%), 6(12,7 \%)$ e 12 $(25,5 \%)$ dos animais, perfazendo 30 éguas com reações entre 1 e $3+(63,8 \%)$. Em contraste, em $17(36,2 \%)$ das 47 éguas com isolamento microbiano não se evidenciou qualquer reação ao CMT.

Tabela 1. Microrganismos identificados em cultura pura ou em associação no leite de 47 éguas

\begin{tabular}{|c|c|c|}
\hline Microrganismo & Frequência absoluta & $\begin{array}{c}\text { Frequência relativa } \\
(\%)\end{array}$ \\
\hline Streptococcus spp. & 11 & 23,40 \\
\hline Staphylococcus aureus & 7 & 14,89 \\
\hline Streptococcus equi & 5 & 10,65 \\
\hline Staphylococcus spp. & 3 & 6,38 \\
\hline Nocardia spp. & 3 & 6,38 \\
\hline Corynebacterium spp. & 2 & 4,25 \\
\hline Staphylococcus hyicus & 1 & 2,12 \\
\hline Arcanobacterium pyogenes & 1 & 2,12 \\
\hline Enterobacter cloacae & 1 & 2,12 \\
\hline Staphylococcus aureus + Enterobacter cloacae & 2 & 4,25 \\
\hline Staphylococcus spp. + Escherichia coli & 2 & 4,25 \\
\hline Streptococcus spp. + Enterobacter cloacae & 2 & 4,25 \\
\hline Streptococcus equi + Citrobacter freundi & 1 & 2,12 \\
\hline Streptococus spp. + Corynebacterium spp. & 1 & 2,12 \\
\hline Streptococcus spp. + Nocardia spp. & 1 & 2,12 \\
\hline Staphylococcus intermedius + Corynebacterium spp & 1 & 2,12 \\
\hline $\begin{array}{l}\text { Staphylococcus spp. }+ \text { Streptococcus } \mathrm{spp} .+ \\
\text { Enterobacter cloacae }\end{array}$ & 2 & 4,25 \\
\hline Enterobacter cloacae + Bacillus spp. + Candida spp. & 1 & 2,12 \\
\hline
\end{tabular}


O perfil de sensibilidade microbiana das 71 linhagens de microrganismos revelou que amicacina $(78,9 \%)$, ceftiofur $(74,7 \%)$, sulfatrimetoprim $(69,0 \%)$ e norfloxacina $(69,0 \%)$ foram os antimicrobianos mais efetivos. Os maiores índices de resistência das estirpes foram observados para penicilina $(64,8 \%)$, gentamicina $(35,2 \%)$, azitromicina $(35,2 \%)$, enrofloxacina $(28,2 \%)$ e florfenicol $(28,2 \%)$ (Tab. 2). A média e a mediana da celularidade do leite das oito éguas sem isolamento de microrganismos, CMT negativas, foram 247 e $259,81 \times 10^{3} \mathrm{CS} / \mathrm{mL}$, respectivamente. Em contraste, a CCS dos 47 animais com isolamento microbiano do leite revelou $1.621,86$ e $1.397,97 \times 10^{3} \mathrm{CS} / \mathrm{mL}$ para média e mediana, variando de 110 a $9.589 \times 10^{3} \mathrm{CS} / \mathrm{mL}$. As éguas infectadas com $A$. pyogenes e $S$. aureus acusaram, respectivamente, 9.589 e $6.320 \times 10^{3} \mathrm{CS} / \mathrm{mL}$.

Tabela 2. Perfil de sensibilidade microbiana na prova de difusão com discos em 71 linhagens de microrganismos isolados no leite de éguas sadias ou portadoras de infecção mamária

\begin{tabular}{lccc}
\hline \multirow{2}{*}{ Antimicrobiano } & \multicolumn{3}{c}{ Número de linhagens $(\%)$} \\
\cline { 2 - 4 } & Resistente & Parcialmente sensível & Sensível \\
\hline Penicilina & $46(64,8)$ & $16(22,5)$ & $9(12,7)$ \\
Sulfatrimetoprim & $22(31,0)$ & $0(--)$ & $49(69,0)$ \\
Gentamicina & $25(35,2)$ & $11(15,5)$ & $35(49,3)$ \\
Azitromicina & $25(35,2)$ & $30(42,3)$ & $16(22,5)$ \\
Ceftiofur & $13(18,3)$ & $5(7,0)$ & $53(74,7)$ \\
Enrofloxacina & $20(28,2)$ & $12(16,9)$ & $39(54,9)$ \\
Amicacina & $15(21,1)$ & $0(--)$ & $56(78,9)$ \\
Florfenicol & $20(28,2)$ & $10(14,0)$ & $41(57,8)$ \\
Norfloxacina & $16(22,5)$ & $6(8,5)$ & $49(69,0)$ \\
\hline
\end{tabular}

Welsh (1984), no Canadá, relatou mastite clínica em duas éguas por Streptococcus zooepidemicus no quarto mês de lactação, as quais apresentavam exsudato purulento em ambas as mamas. Estudo realizado na Alemanha entre 1985 e 1988, com 33 éguas de várias raças e idades (4 e 14 anos) apresentando mastite aguda, identificou predominantemente: S. aureus, Escherichia coli e os gêneros Streptococcus e Klebsiella (Bostedt et al., 1988). McCue e Wilson (1989), em revisão de 28 casos de mastite clínica em éguas, isolaram: Streptococcus spp. (36,8\%), Staphylococcus spp. (14,5\%) e Actinobacillus suis (10,5\%). No Brasil, Prestes et al. (1999) estudaram 38 amostras de leite de éguas e identificaram diferentes linhagens de microrganismos, distribuídos como se segue: 17 $(33,3 \%) \quad$ Staphylococcus spp., $15 \quad(29,4 \%)$ Streptococcus spp., $10(19,6 \%)$ Corynebacterium spp., 5 (9,8\%) Bacillus spp., 4 (7,9\%) Pasteurella spp., 4 (7,9\%) Candida spp., 4 $(7,9 \%)$ Enterobacter cloacae e 4 (7,9\%) Shigella spp. À semelhança dos ruminantes domésticos, foi observado no presente estudo predomínio de microrganismos contagiosos dos gêneros Staphylococcus, Streptococcus e Corynebacterium. Este grupo de bactérias possui como hábitat a pele e mucosas dos animais e pode estabelecer infecções oportunistas secundárias a traumatismos nas mamas ou via ascendente pelos canais dos tetos, pelo próprio ato de mamar dos potros (Smith, 2003; Radostits et al., 2007). Somente duas dentre as 55 éguas apresentaram sinais de mastite clínica, com isolamento de $S$. aureus e A. pyogenes. Este achado concorda com outros autores que também se referem à baixa ocorrência de casos clínicos de mastite infecciosa em éguas (Prestes et al., 1999; Smith, 2003).

No presente estudo, foi observada moderada concordância entre os animais reagentes ao CMT escores 1 a $3+(63,8 \%)$ e o isolamento microbiano do leite. Este achado indica certa limitação do uso desta técnica - padronizada para bovinos - em éguas, como indicativo de infecção mamária. Em ruminantes domésticos, os testes indiretos utilizados como indicativos de infecção mamária - particularmente o CMT e CCS - são fundamentados no aumento da celularidade do leite, principalmente como consequência do elevado afluxo de neutrófilos. Para o exame de amostras individuais do leite de vacas considera-se normal entre 100 e $250 \times 10^{3} \mathrm{CS} / \mathrm{mL}$ de leite, enquanto valores $\geq 500 \times 10^{3} \mathrm{CS} / \mathrm{mL}$ são indicativos de infecção (Santos e Fonseca, 2007). Apesar do uso pontual 
do CMT e CCS em éguas lactantes (Prestes et al., 1999; Santos et al., 2005; Reis et al., 2007; 2009), estes procedimentos não estão padronizados para a espécie equina (Smith, 2003).

A CCS de éguas pode ser realizada pela contagem microscópica em lâminas (Prestes et al., 1999) e, recentemente, tem sido realizada eletronicamente em aparelhos de citometria de fluxo (Reis et al., 2009), que permitem quantificar grande número de amostras em curto período de tempo (Santos e Fonseca, 2007). No entanto, a contagem eletrônica não está padronizada para a espécie equina. No Brasil, Prestes et al. (1999) avaliaram CCS do leite de 38 éguas em lactação aparentemente sadias ou com infecções subclínicas, utilizando a contagem de células em lâminas, e constataram que somente três $(9,6 \%)$ animais resultaram em contagens acima de $500 \times 10^{3} \mathrm{CS} / \mathrm{mL}$. Reis et al. (2009) também encontraram baixa celularidade $\left(16,4 \times 10^{3} \mathrm{CS} / \mathrm{mL}\right)$ no leite de éguas aparentemente saudáveis da raça Mangalarga. De maneira similar, oito das 55 éguas amostradas sem sinais aparentes de infecção, CMTnegativas, acusaram contagens celulares inferiores a $250 \times 10^{3} \mathrm{CS} / \mathrm{mL}$, valor que seria considerado dentro da normalidade para o leite de vacas (Santos e Fonseca, 2007).

Reis et al. (2009) encontraram valores elevados nas contagens celulares $\left(2.550 \times 10^{3} \mathrm{CS} / \mathrm{mL}\right)$ e CBT em éguas Mangalarga Marchador com infecção mamária. De forma similar, em 47 das éguas amostradas nas quais se obteve isolamento microbiano do leite, foram encontradas contagens médias de $1.621,86 \times 10^{3} \mathrm{CS} / \mathrm{mL}$. Este valor médio de celularidade nas éguas seria superior a $500 \times 10^{3} \mathrm{CS} / \mathrm{mL}$, considerado indicativo de infecção para vacas, mostrando certa similaridade entre a resposta celular em vacas e éguas com infecção na glândula mamária. Apesar da alta CCS nas 55 éguas estudadas, somente dois animais exteriorizaram mastite clínica. Tal achado pode ser creditado ao predomínio dos microrganismos contagiosos nas 55 éguas estudadas, visto que este grupo de bactérias está adaptado às mucosas e conjuntivas de animais domésticos e, ao contrário dos ambientais, as infecções pelos contagiosos geralmente ocorrem sob a forma subclínica (Ribeiro, 2008).

Nas duas éguas com mastite clínica amostradas no presente estudo, com isolamento microbiano de A. pyogenes e $S$. aureus, foram observadas contagens celulares, respectivamente, de 9.589 e $6.320 \times 10^{3} \mathrm{CS} / \mathrm{mL}$, significativamente superiores às observadas para as éguas sadias, CMTpositivas e/ou com isolamento de outros microrganismos. Tal resultado pode ser justificado em virtude de estes microrganismos apresentarem em comum grande número de fatores de virulência, estabelecerem infecções intracelulares e apresentarem alta quimiotaxia por fagócitos - particularmente neutrófilos -, que resultam em infecções com alta celularidade no leite (Santos e Fonseca, 2007).

$\mathrm{O}$ teste de sensibilidade in vitro aos antimicrobianos revelou que amicacina, ceftiofur, sulfatrimetoprim e norfloxacina foram os mais efetivos, podendo ser indicados como fármacos de escolha no tratamento de infecções mamárias em éguas. Em contraste, foi observada alta resistência das linhagens frente à penicilina e, secundariamente, à gentamicina, à azitromicina, à enrofloxacina e ao florfenicol. Curiosamente, estes antimicrobianos que se mostraram pouco efetivos frente aos isolados são princípios ativos indicados no tratamento de diferentes afecções em equinos (Radostitis et al., 2007), incluindo mastite em éguas (Bostedt $e t$ al., 1988; McCue e Wilson, 1989). Este achado reforça, de maneira similar às outras espécies de animais de produção, a necessidade da instituição dos tratamentos mamários em éguas com 0 respaldo dos testes in vitro de sensibilidade microbiana, com vistas a otimizar a cura microbiana (Ribeiro, 2008). Os achados do presente estudo permitiram inferir, para a baixa ocorrência de mastite clínica em éguas, o predomínio de microrganismos contagiosos nas infecções mamárias, a moderada associação entre a CCS e o cultivo microbiano, certa similaridade da resposta de células somáticas das éguas com as vacas, assim como a necessidade da instituição do tratamento mamário com respaldo no antibiograma.

Palavras-chave: égua, mastite, California Mastitis Test, contagem de células somáticas 


\begin{abstract}
Routine diagnosis methods used in bovine mastitis were studied in 55 mares in lactation. The findings of strip cup test, California Mastitis Test-CMT, electronic somatic cell count-CCS, microbiological culture, and in vitro antimicrobial susceptibility profile of isolates were discussed. Streptococcus spp., Staphylococcus spp, and enterobacteria were the most common microorganisms isolated in health and CMT-positive mammary glands. Staphylococcus aureus and Arcanobacterium pyogenes were identified in two mares presenting clinical mastitis. Mean somatic cell count of eight mares without presence of microorganisms in milk was $247.57 \times 10^{3} / \mathrm{mL}$ and $1.621,86 \times 10^{3} / \mathrm{mL}$ in 47 mares with positive microbiological culture. Moderate concordance (63.8\%) between positive reactions in CMT (1 to $3+)$ and microbiological culture was observed. Amicacin (78.9\%), ceftiofur (74.7\%), sulpha-trimetoprim $(69,0 \%)$ and norfloxacin (69.0\%), were the most effective drugs, while resistance of isolates was mainly observed against penicillin (64.8\%), gentamycin (35.2\%), azithromycin (35.2\%), enrofloxacin (28.2\%), and florfenicol (28.2\%).
\end{abstract}

Keywords: mare, mastits, etiology, California Mastitis Test, somatic cell count

\section{REFERÊNCIAS BIBLIOGRÁFICAS}

ARASHIRO, E.K.N.; TEODORO, V.A.M.; MIGUEL, E.M. Mastite bovina: importância econômica e tecnológica, 2008. Disponível em: (www.cienciadoleite.com.br). Acessado em: 21 jul. 2010.

BOSTEDT, H.; LEHMANN, B.; PEIP, D. Mastitis in mares. Tierarztliche Praxis, v.16, p.367-71, 1988.

CLINICAL and laboratory standards institute. Performance Standards for Antimicrobial Disk Susceptibility Test (CLSI-NCCLS). 9.ed. Pennsylvania, 2006.

KOTERBA, A.M.; DRUMOND, W.H.; KOSCH, P.C. Equine Clinical Neonatology, USA : Lea \& Febiger, 1990. 844p.

McCUE, P.M.; WILSON, W.D. Equine mastitis - a review of 28 cases. Equine Vet. J., v.21, p.351-353, 1989.

MORAIS, M.T.; SIMONE, E.M.; ROMANO, L.A. Estudo da composição do leite de égua e comparação com o leite da mulher. Hora Vet., ano 16, p.37-43, 1997.

PRESTES, N.C.; LANGONI, H.; CORDEIRO, L.A.V. Estudo do leite de éguas sadias ou portadoras de mastite subclínica, pelo Teste de Whiteside, análise microbiológica e contagem de células somáticas. Braz. J. Vet. Res. Anim. Sci., v.36, 1999.

QUINN, P.J.; MARKEY, B.K.; CARTER, M.E. et al. (Eds). Microbiologia Veterinária e Doenças Infecciosas. Porto Alegre: Artmed, 2005. 512p.
RADOSTITS, O.M.; GAY, C.C.; HINCHCLIFF, K.W. et al. (Eds). Veterinary medicine: A textbook of the diseases of cattle, horses, sheep, pigs, and goats. 10.ed. Philadelphia: Saunders, 2007. p.724-725.

REIS, A.P.; MESQUITA, A.J.; MOREIRA, C.H.G. et al. Composição do leite de éguas da raça Mangalarga Marchador. Rev. Inst. Adolfo Lutz, v.66, p.130-135, 2007.

REIS, A.P.; MESQUITA, A.J.; SANTOS, K.R.P. et al. Avaliação da contagem de células somáticas e contagem bacteriana total do leite de éguas da raça Mangalarga Marchador. Vet. Zootec., v.16, p.204-212, 2009.

RIBEIRO, M.G. Princípios terapêuticos na mastite em animais de produção e de companhia. In: ANDRADE, S.F. (Ed.). Manual de Terapêutica Veterinária. 3.ed. Roca: São Paulo, 2008. p.759-771.

SANTOS, E.M.; ALMEIDA, F.Q.; VIEIRA, A.A. $e t$ al. Lactation in Mangalarga Marchador mares: yield production and composition of milk, and weight gain of suckling foals. Rev. Bras. Zootec., v.34, p.627-634, 2005.

SANTOS, M.V.; FONSECA, L.F.L. (Eds.) Estratégias para controle de mastite e melhoria da qualidade do leite. São Paulo: Manole, 2007. 314p.

SMITH, PB. Large animal internal medicine. 4.ed. St Louis: Mosby, 2003. p.937-998.

WELSH, R.D. The significate of S. zooepidemicus in the horse. Equine Pract., v.6, p.6-16, 1984. 